\title{
Effect of biocharand ameliorant on yield and quality of watermelon
}

\section{(Citrulluslanatus)}

\author{
XiaoweiZhai $^{1, a}$, HefangWang ${ }^{1, b}$, Lei Chen ${ }^{1, c}$ and HaoZheng ${ }^{1, d, *}$ \\ ${ }^{1}$ College of Environmental Science and Engineering, Ocean University of China, Qingdao 266100, \\ China, \\ azhaixiaoweismile@163.com, 'bwhine@126.com, 'ludongdaxuechenlei@163.com, \\ dzhenghao2013@ouc.edu.cn \\ * Corresponding author: zhenghao2013@ouc.edu.cn; 0532-66781068
}

\begin{abstract}
Keywords:ameliorant, peanut-shell biochar, watermelon, yield, quality
Abstract. Application of biochar(BC)and biochar-based ameliorant (BCA) to agricultural soilhasbeen proved to exert beneficialeffects onsoilfertility and crop yield.However,little information is available about theirinfluencesonfruit quality. WeinvestigatedtheeffectofBC or BCAon Watermelon(Citrulluslanatus)growth andqualityin a fieldexperiment in Ningxia. BC applicationsignificantlydecreasedthe fresh biomass of shoot by $45.7 \%$. BCA dramatically decreased the fruit yieldof watermelon by $20.7 \%$ compared with that of CK. Both of BC and BCA had noinfluence on the sweetness and rind thickness of watermelon. Thelack of significant differencebetween biochar treatments andcontrolsfortoughness of peel and pulp was noted. These observations are useful for screening desired BC and BCA to produce positiveeffects on both of yield and quality of watermelon.
\end{abstract}

\section{Introduction}

Biochar (BC), as a novel soil amendment, is pyrolyzedfrom biomass under oxygen-limited condition[1]. Biochar application to agricultural soil has recently been proposed as a feasible and effective win-win strategy to simultaneously improve soil water holding capacity[2], enhance soil fertility, decrease nutrient leaching and stimulate soil microbial activity [3], and thus increase crop productivity [4].

The development of agriculture is closely related to the use of chemical fertilizers, which increasesthe crop yield significantly. However, there are still a series of problems unsolved.For example,the inefficiency utilizationof fertilizer ledto the waste of agriculture resources, and the overusealso caused the eutrophication of water. Recent studies have demonstrated that the combination application of biochar and chemical fertilizer promises to solve these problems[5]. Moreover, the biochar-basedamendment(BCA)mixed with biochar and chemical fertilizer could increase the yield of agricultural production[6]. It is worth noting that many experiments have observed positive effects on cropproductionwith BCA application.

However, there are few researches evaluating the impact of BCA on quality. Watermelon (Citrulluslanatus) is a greatly popular summertime fruit, of which the rind thickness affects the yield of edible pulp and the sweetness and pulp toughnesspossible determine the taste quality. The objective of this study was to investigate theeffectsofBC and BCAon yield and quality of watermelon. 


\section{Materials and Methods}

Materials. Thepeanut shellbiochar (BC) was produced at $350{ }^{\circ} \mathrm{Cfor} 2 \mathrm{~h}$ under the condition of $\mathrm{N}_{2}$. The biochar was ground to pass a sieve. The biochar-based ameliorant (BCA) was made of BC, peanut shellpowder, ammonium nitrate and water. Watermelon(Citrulluslanatus)was chosen as the tested plant.

Experimental site and experimental design. The field experiment was performed in experimental base in Ningxia Academy of Agricultural and Forestry Sciences.Tosupplysufficientnutrientsduringthe experiment, the goat and dairy manures were applied to the soil as base fertilizer.Three treatments were established with three replicates: no BC and BCA amendment, only BC $(1.5 \%$, w/w), only BCA $(1.5 \%$, w/w), hereafter referred to as $\mathrm{CK}, \mathrm{BC}, \mathrm{BCA}$, respectively.Watermelonswere grown on the filed plots with plant density of 650 per acre on 12May, 2014.

Plantsamplingandanalysis.Atmaturity,watermelonswereharvestedon15 August,2014.Four samples in each duplicate of every treatment were selected to measurethe fresh biomass of shootand the fruit yieldof watermelon.Additionally, the rind thickness wasdetermined and the sweetnessof watermelonwasanalyzedby refractometer. The toughness of pericarp and pulp were measuredby fruit hardness tester.

Results are expressed as the average of three replicates withstandard deviation. Significant differenceswere tested using least significant difference (LSD) $(P<0.05)$ byStatistical Product and Service Solutions (SPSS 20.0).

\section{Results and discussion}

In order to study the effects of BC and BCA on the yield of watermelons, we measured the fresh biomass of shoot and the fruit yield (Fig.1). It turned out that BCsignificantlydecreased the fresh biomass of shoot by $45.7 \%$ compared with that of CK, but BCAhad no influence on that.However, the increasing of $57.0 \%$ fresh biomass was observed in BCA treatment compared with that in BC treatment. The possible reason is that the $\mathrm{N}$ content of BCAis more than that of $\mathrm{BC}$, which stimulated the photosynthesis. Nevertheless, the application of BCA dramatically suppressedthe fruit yield of watermelonby $20.7 \%$ compared with CK. The mechanism could be the fact that a large quantities of nutrientsreleased from BCA stimulated the leaf growth of watermelon, which inhibitedthe fruit yield.
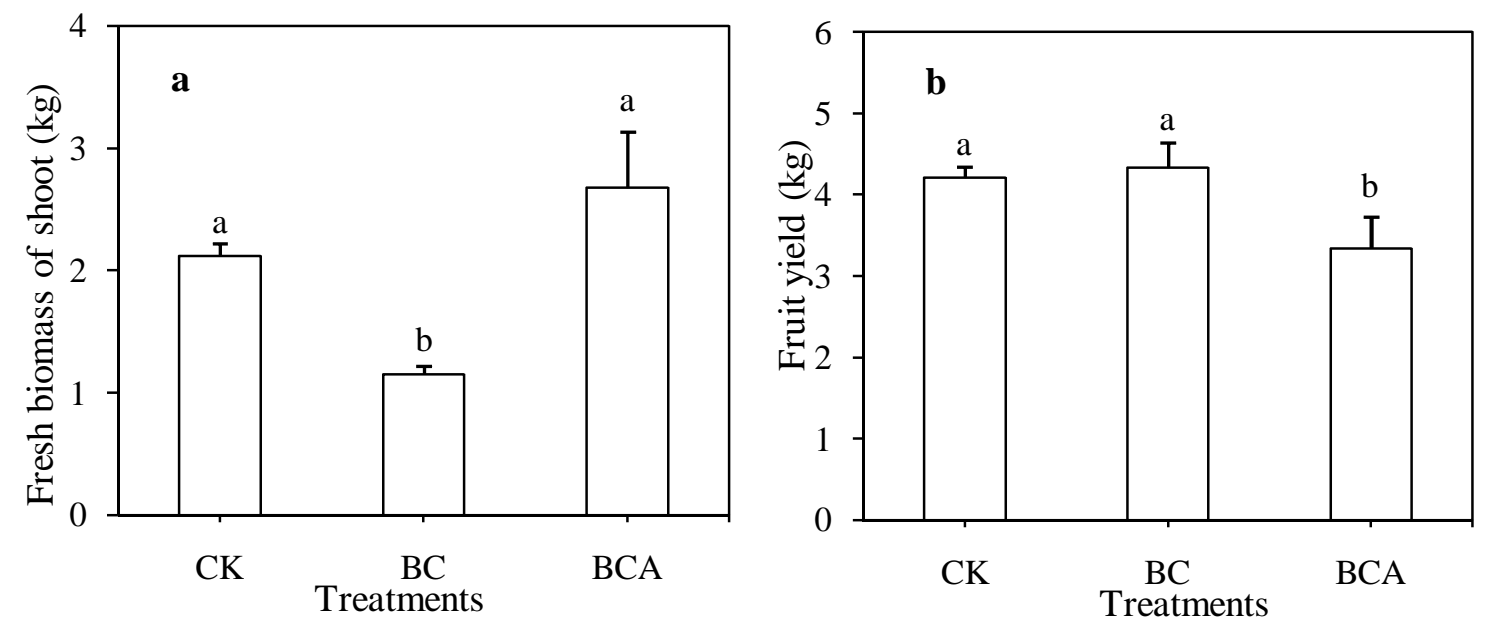

Fig. 1 Effects of BC and BCA additionsonfresh biomass of shoot (a) andfruit yield (b). The different lowercase letters represent significant difference between the treatments $(P<0.05)$. 
For further study the influence on quality of the watermelon, this study aimed at sweetness, rindthickness and the toughness of pericarp and pulpto discuss the quality of watermelon. Unexpectedly,BC and BCA additions resulted in no significant effect on the sweetness (Fig. 2a), and the similar trendancy of rind thickness was observed (Fig. 2b).Schmidtetal.[7]also foundlack of significant difference offruits qualitybetween biochar treatments andcontrol. And the BC slightly improved the toughness of peel and pulp, but led to no significant difference compared with that in CK and BCA treatments (Fig. 3).
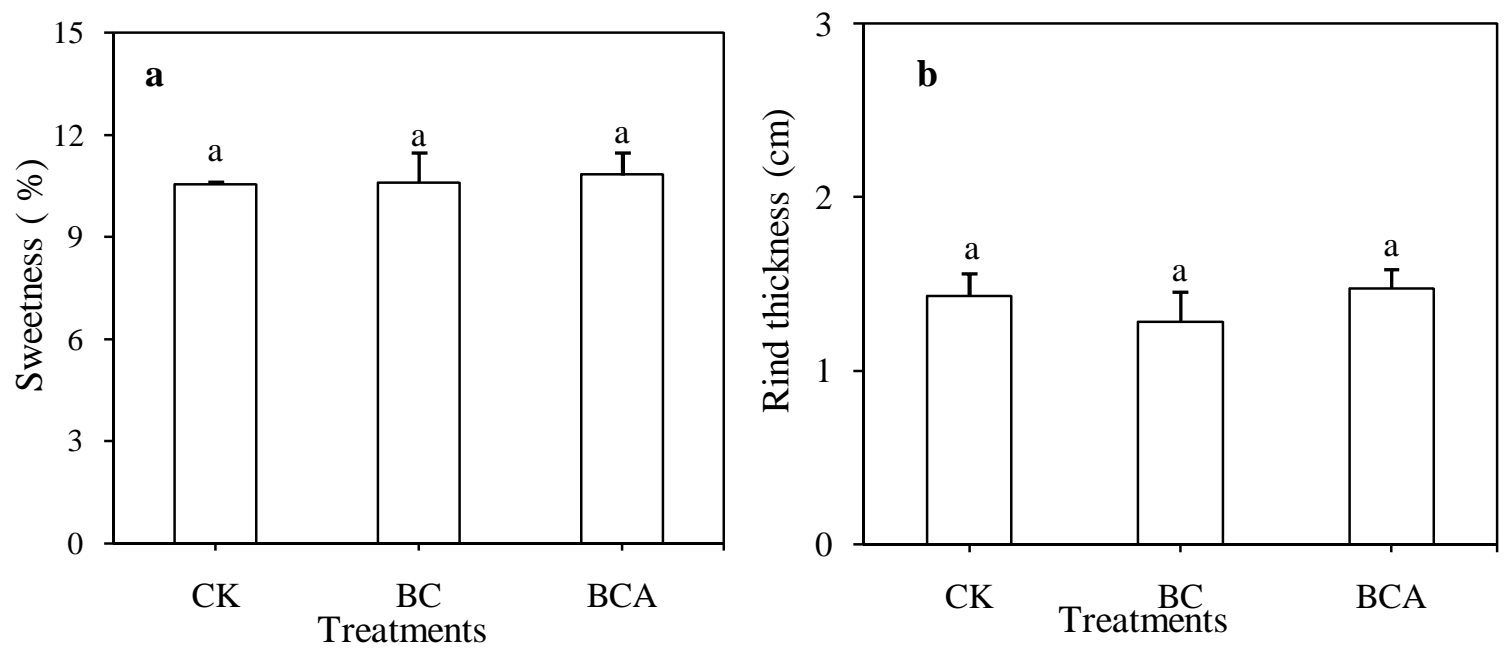

Fig. 2Effects of BC and BCA additionsonsweetness (a) andrind thickness (b). The different lowercase letters represent significant difference between the treatments $(P<0.05)$.
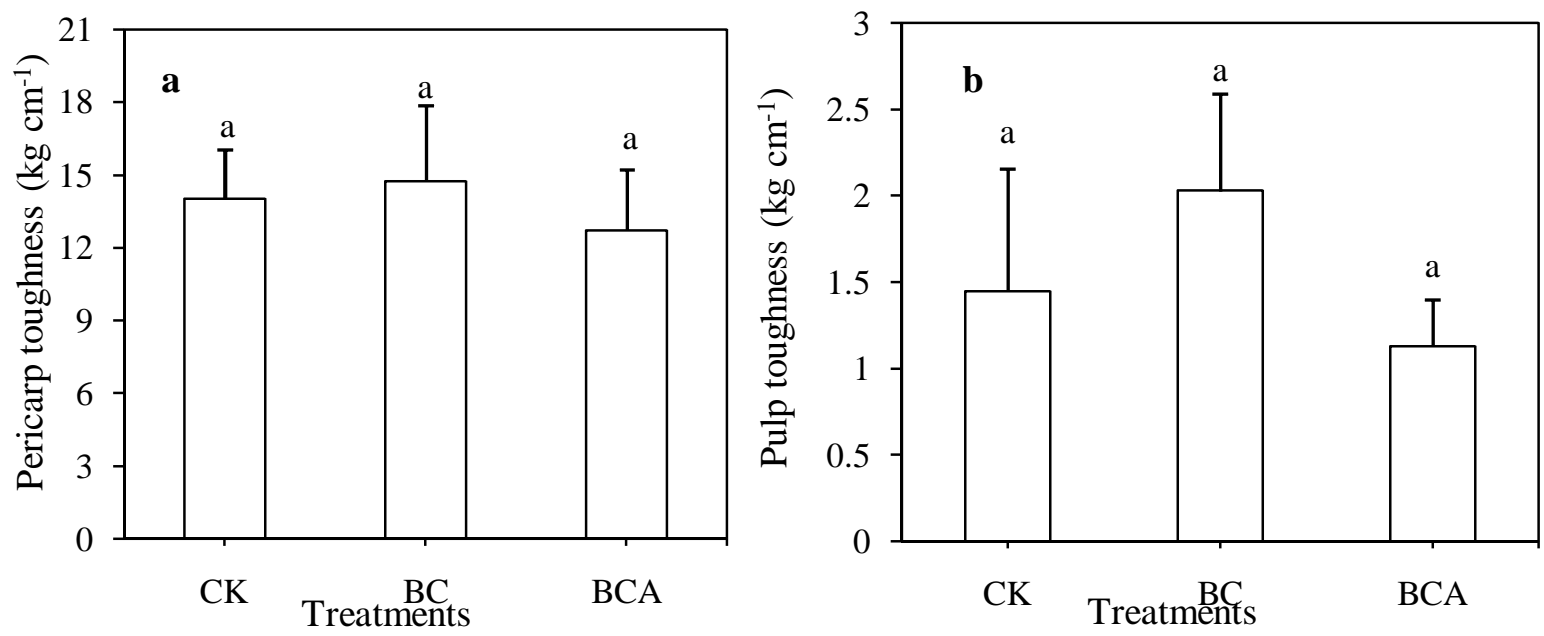

Fig. 3Effects of BC and BCA additionsonpericarp toughness (a) andpulp toughness (b). The different lowercase letters represent significant difference between the treatments $(P<0.05)$.

\section{Conclusions}

This study investigated the effects of BC and BCA on the yield and quality of watermelon. The result confirmed that $\mathrm{BC}$ and $\mathrm{BCA}$ inhibited thefresh biomassof shoot and fruit yield, respectively. Both of BC and BCAapplicationdid not produce adverse influences on the sweetness and rind thickness of watermelon. In addition, no significant difference of the toughness of pericarp and pulp was noted between $\mathrm{BC}, \mathrm{BCA}$ and $\mathrm{CK}$. 


\section{Acknowledgements}

Thisstudy was supported bythe Ningxia Science-technology Support Plan Projects(No. 2013Zys149), the Indigenous Programs from Ningxia Academy of Agricultural and Forestry Sciences (No. nkyg-13-11) and National Natural Science Foundation of China (41406085, 41325013).

\section{References}

[1] Sohi, S.P.Carbon storage with benefits: ScienceVol. 338(2016), p. 1034-1035.

[2] Busch,D., et al. Simple biotoxicity tests for evaluation of carbonaceous soil additives: establishment and reproducibility offour test procedures: J Environ Qual Vol. 41 (2012), p. 1023-1032.

[3] Rutigliano, F.A., et al. Effect of biochar addition on soil microbial community in a wheat crop: European Journal ofSoil Biology Vol. 60 (2014), p. 9-15.

[4] Vaccari, F.P., et al.Biochar as a strategy to sequester carbon and increase yield in durum wheat: European Journal of Agronomy Vol. 34(2011), p. 231-238.

[5]Novak, J.M., et al. Designing relevant biochars as soil amendments using lignocellulosic-based and manure-based feedstocks: Journal of Soils and Sediments Vol.14(2013), p. 330-343.

[6]Dong, D., et al.Effects of biochar amendment on rice growth and nitrogen retention in a waterlogged paddy field: J Soils SedimentsVol. 15 (2015), p. 153-162.

[7]Schmidta, H.-P., et al. Biochar and biochar-compost as soil amendments to a vineyard soil: Influences on plant growth, nutrient uptake, plant health and grape quality: Agriculture, Ecosystems and Environment Vol. 191 (2014), p. 117-123. 